\title{
The BMJ Awards: celebrating excellence
}

\author{
Fiona Godlee editor in chief
}

The BMJ

This week both houses of parliament have put their minds to the NHS funding crisis (p 127). A House of Lords committee hearing on the sustainability of NHS funding was told by Chris Hopson, chief executive of NHS Providers, that the health service had reached a "tipping point" where it was being asked to deliver services "that it simply cannot carry on delivering for the funding available."

Also in this issue Andy Cowper (p 130) reports that the pressure on the health service in England continues to build and its performance to suffer, made more acute by cuts to social care (p 130). What was once considered "winter pressure" is now experienced all year round, making winter the new normal, he says. As for the extra money from the government, it's not $£ 10 \mathrm{bn}$, as we are repeatedly told by the Department of Health, but nearer $£ 4.5 \mathrm{bn}$, says a new report from the health select committee. This won't fill the gap.

And yet the rhetoric from No 10 Downing Street looks unlikely to change. There will be no more money. News reports of a meeting last week said that the NHS chief executive, Simon Stevens, had to contend with being lectured by the prime minister, who advised him to learn from how she and our new chancellor had cut spending at the Home Office and the Department of Defence. On the face of it, this comparison might seem reasonable. But it isn't. It takes no account of the rise in demand for health and social care from our ageing population-a
$33 \%$ rise in the number of people aged 85 or over in the past 10 years, says Cowper. I don't know in what terms Stevens replied to Theresa May, but I hope he asked her how having more elderly people would increase crime or the risk of an invasion. Given this extraordinary pressure, and its effect on morale and working conditions, the BMJ Awards this year seem particularly important. They offer us all a chance to celebrate the professionalism, commitment, creativity, and hard work of healthcare teams across the UK. With 15 categories, we hope you'll find one that fits the good work you are doing. The stories about last year's winners will give an idea of the sorts of things our expert judges are looking for (http://bit.ly/2eqLG0n), and if you're in any doubt about entering you can contact the awards team (awards@bmj.com). As Nigel Hawkes explains (p 139), winning an award is not just a one night wonder, although the awards night is wonderful. Winning, and even being shortlisted, can change things profoundly, giving much deserved visibility to the many excellent and innovative ways in which UK healthcare is designed and delivered. I look forward to another inspiring year.

PULL QUOTE—Even being shortlisted can change things profoundly, giving much deserved visibility to the many excellent and innovative ways in which UK healthcare is designed and delivered 